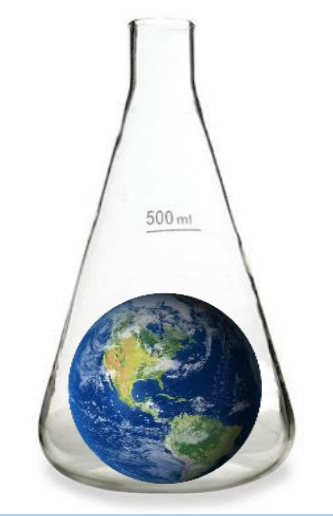

\title{
Bridging the gap: Using geochemical data to integrate geology and chemistry in $\mathrm{K}$ - 12 Education
}

Stephen Kaczmarek, Peter Voice, Heather Petcovic, and William

B. Harrison III

Department of Geological and Environmental Sciences and Michigan Geological Repository for Research and Education

Western Michigan University
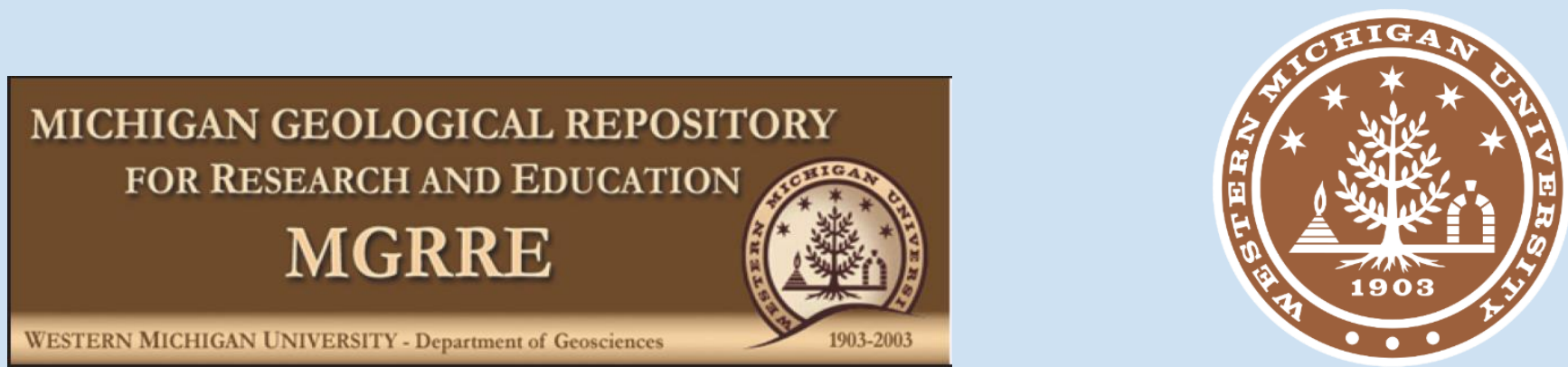


\section{Bridging the Gap Workshop}

- Funded through a NSF Instrumentation \& Facilities Grant

- Supported purchase of Bruker Handheld X-ray Fluorescence Spectrometer (HHXRF)

- Training Undergraduate and Graduate students to use the HHXRF to acquire data

- Develop workshop materials (lesson plans, activities, displays)

- Travel stipends for teacher participants

- August 2017 Workshop - 15 participants

- August 2018 Workshop - in preparation (37 interested teachers) 


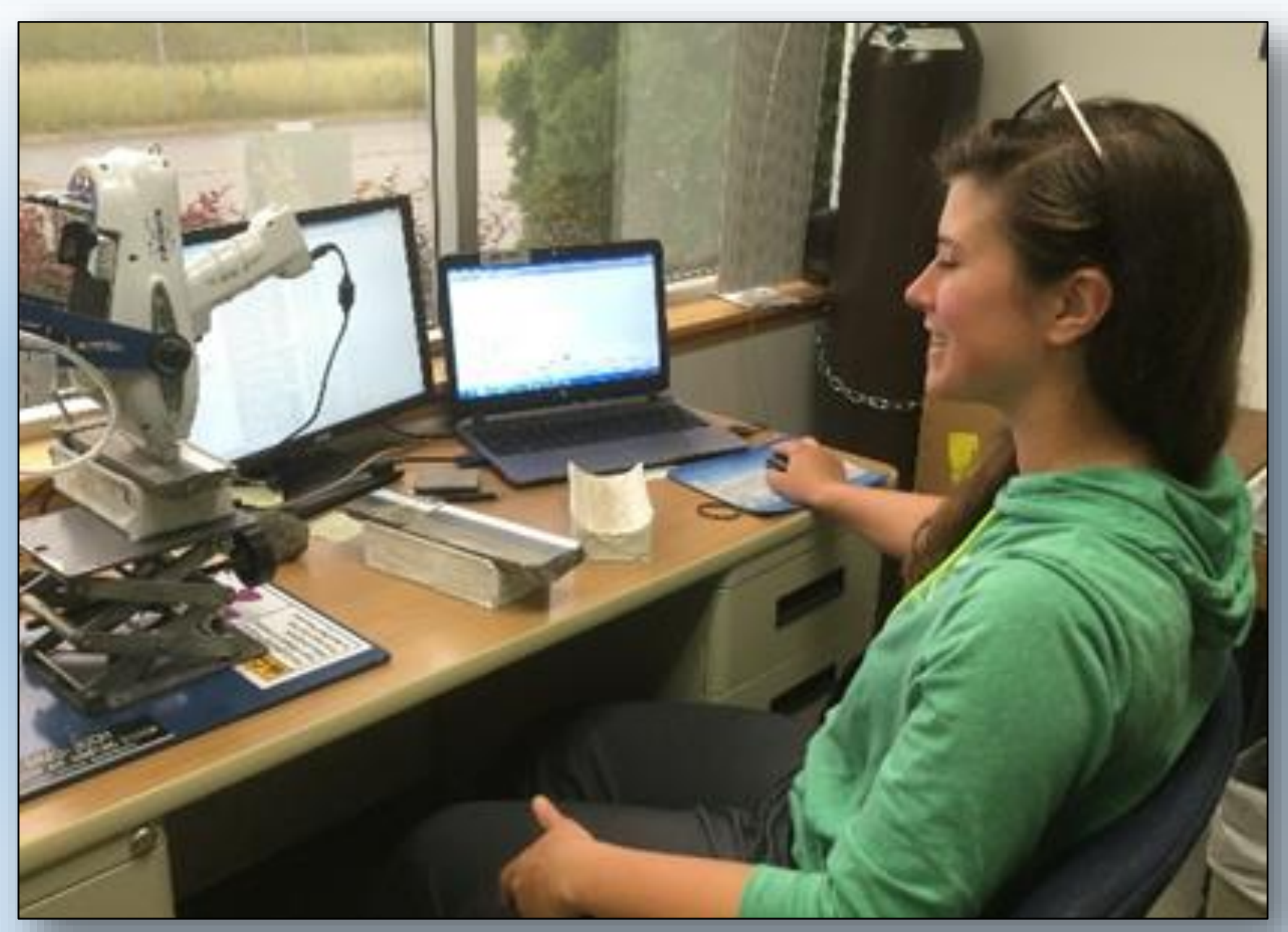

One of our students analyzing a core sample with the HHXRF 


\section{Workshop Objectives}

- Increase familiarity with the concept of using geological materials as sources of quantitative chemical data

- Better appreciate the relationship between common geological materials, their bulk chemical composition, and common societal uses

- Gain a basic understanding of how X-ray fluorescence spectrometry can be used to determine the chemical composition of geological materials

GEOLOGY

Rocks
Minerals

CHEMISTRY

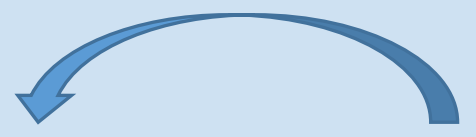

政


Workshop

Agenda

- Short lectures on Earth Materials, Michigan Geology, and X-Ray Fluorescence theory

- Tour of facility

- Hands-on activities including Pet Rock

- Teacher-led discussion, brainstorming, and lesson plan creation

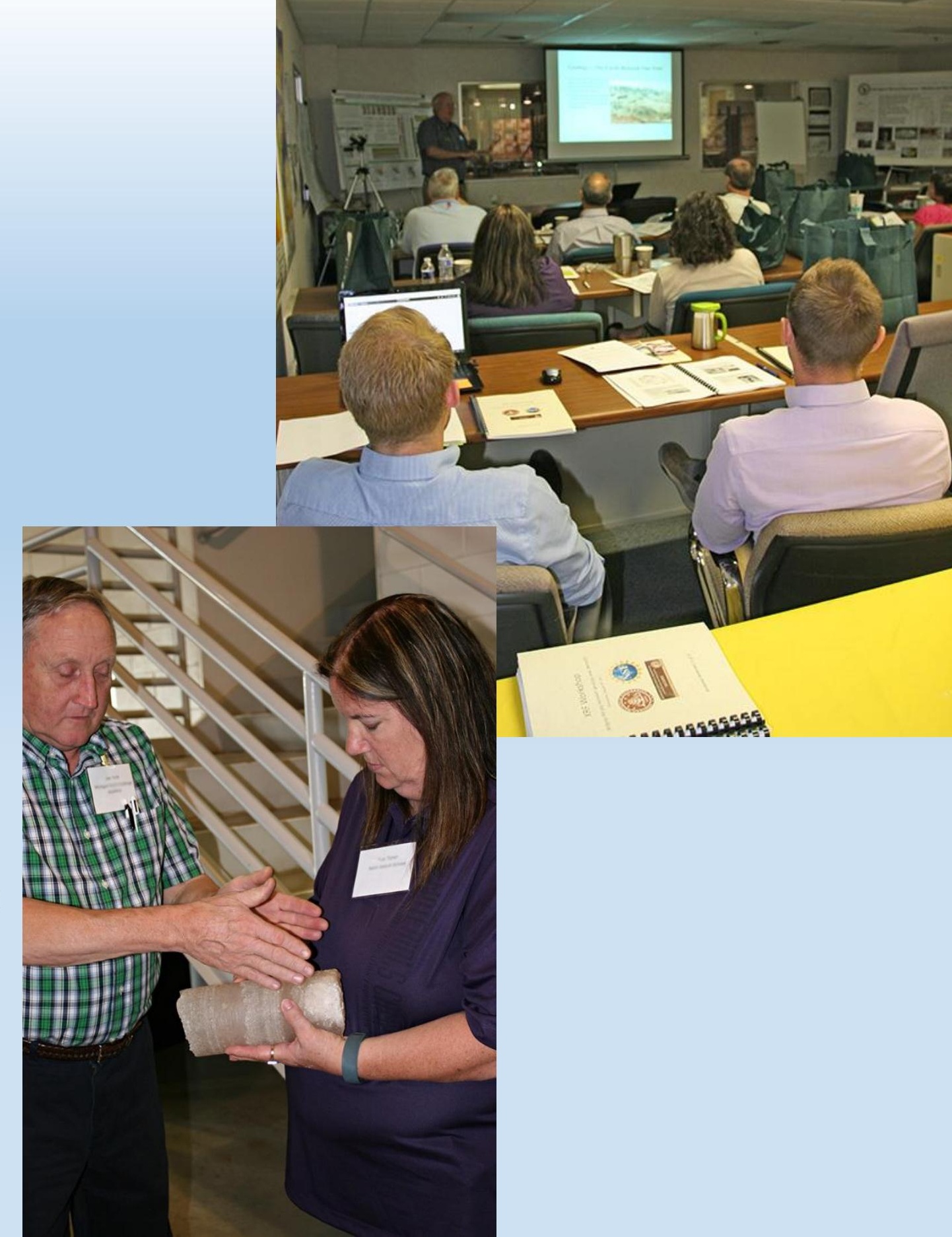




\section{Teacher Recruitment}

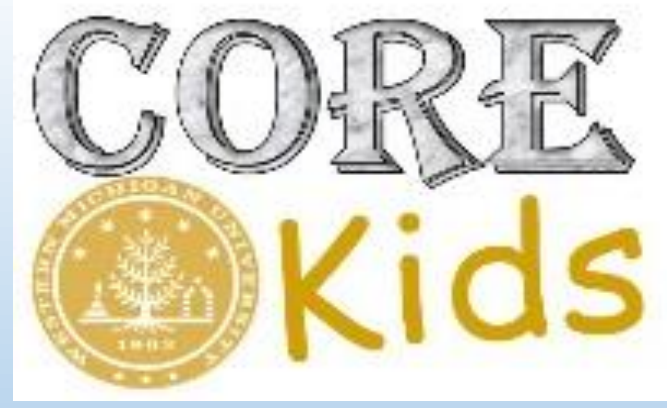

- Partnerships with local teachers associations facilitated advertising/recruitment for workshop

- Relationships through existing outreach activities

- 21 teachers interested in 2017 workshop

- 37 for the 2018 workshop
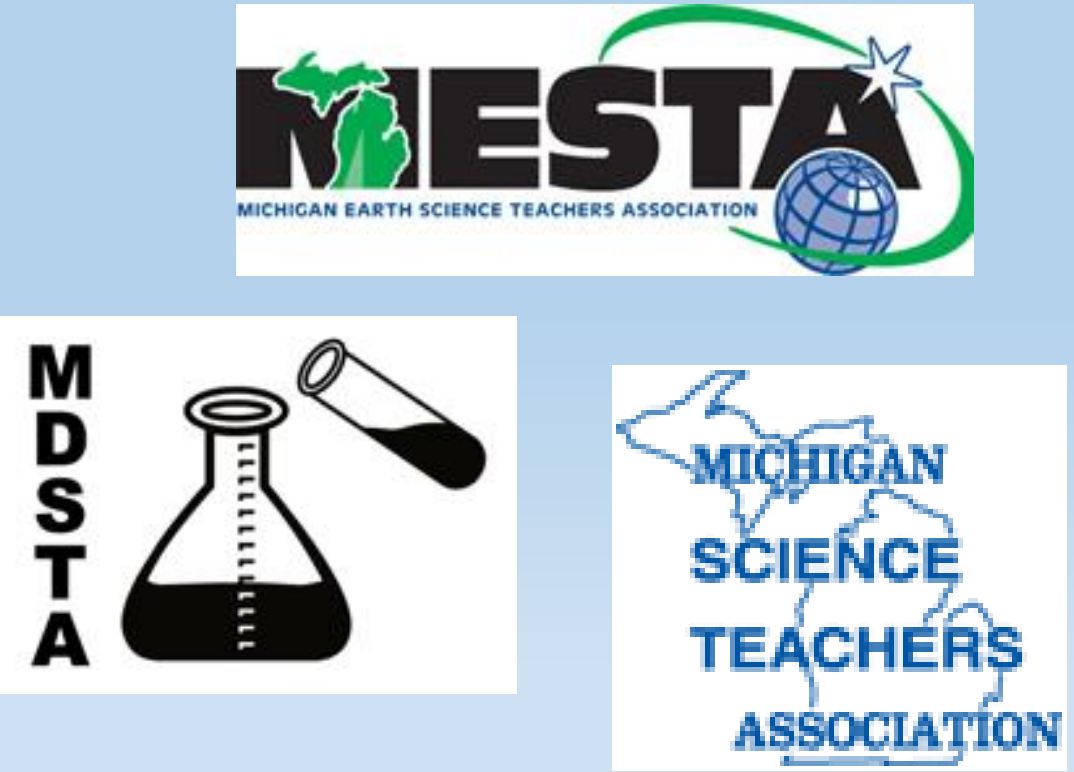

How do we fill the seats????
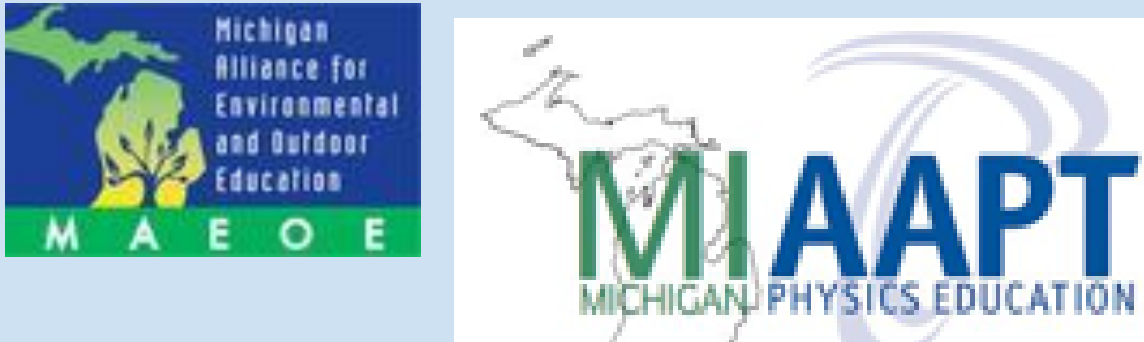


\section{Workshop Participants}

- 15 teachers

- Grade Levels taught - 5 to 12 - mostly at High School level

- Integrated Science, Earth Science, Biology, Math, Chemistry (Honors, Intro, AP), Physics, Astronomy, STEM, Meteorology, Environmental Science

- Mix of public, private, and charter schools represented including a diverse cross section of Urban, Suburban and Rural Schools (primarily Southern Lower Peninsula)

- 53\% Female; majority Caucasian/White

- Wide range of experience -3 to 40 years 


\section{Hands-on Activities}

- Variety of Topics

- Powder Problem

- Fossilization

- Pet Rock

- Forensic XRF

Leslie's Pet Rock - an Icelandic Basalt:

- Alien Agua

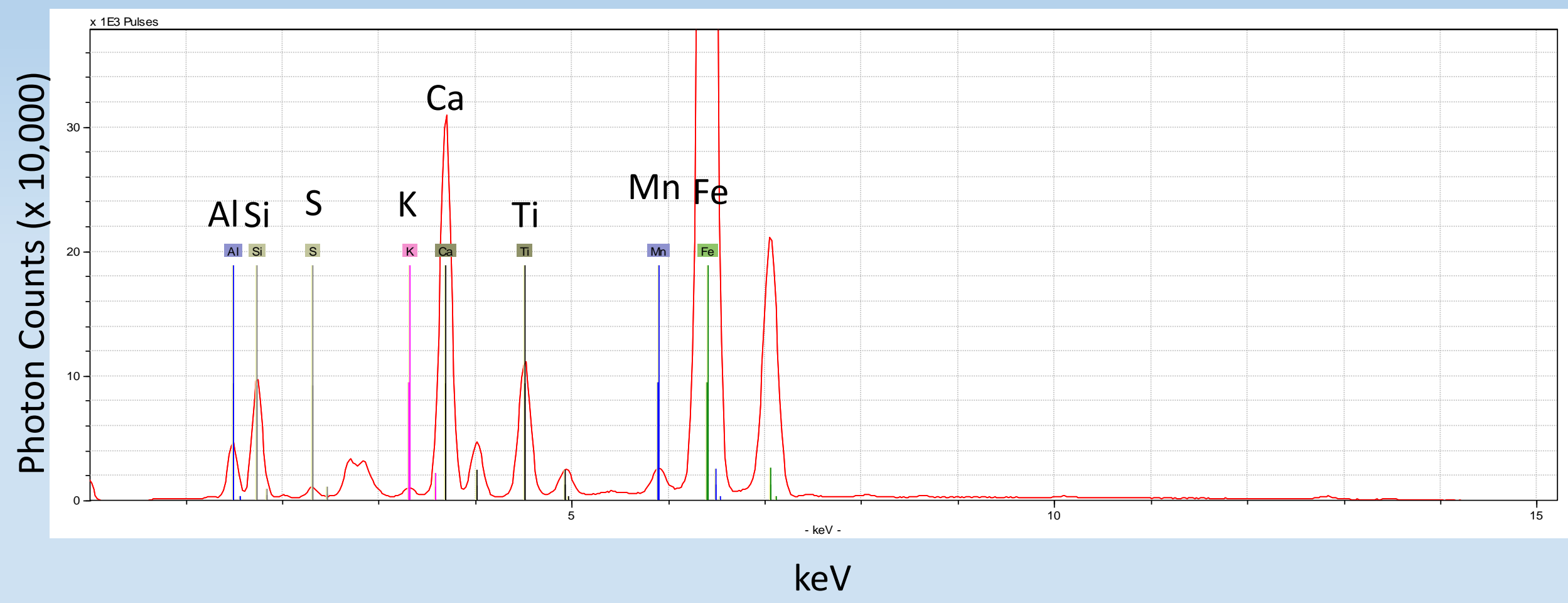


A.

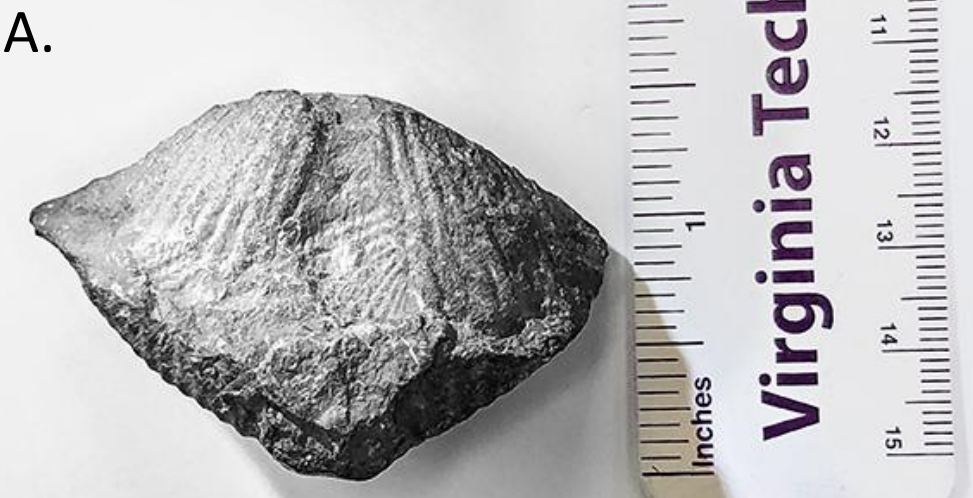

B.

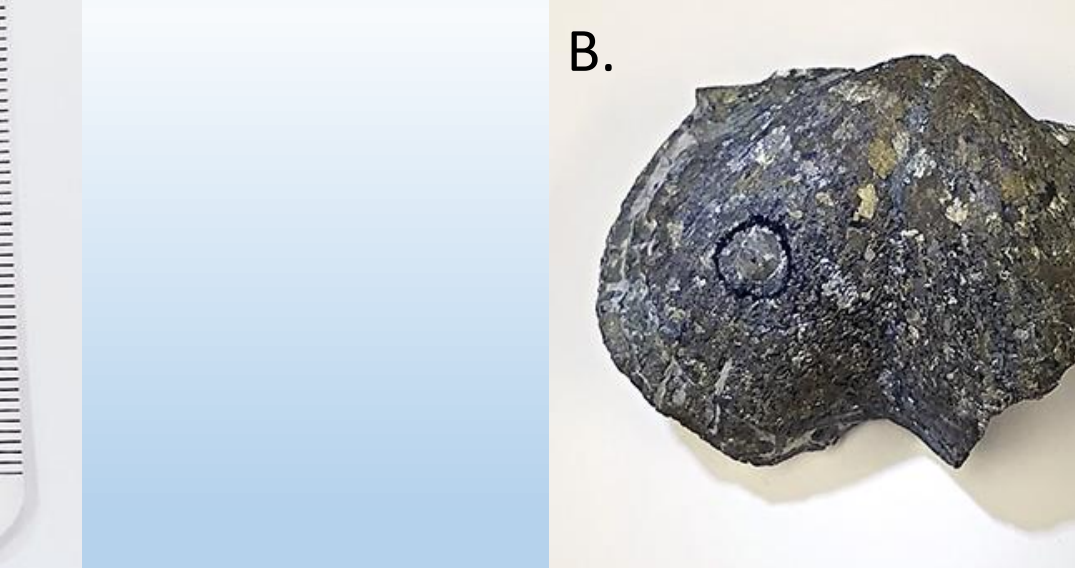

Which Brachiopod is more likely to exhibit the following chemical composition?

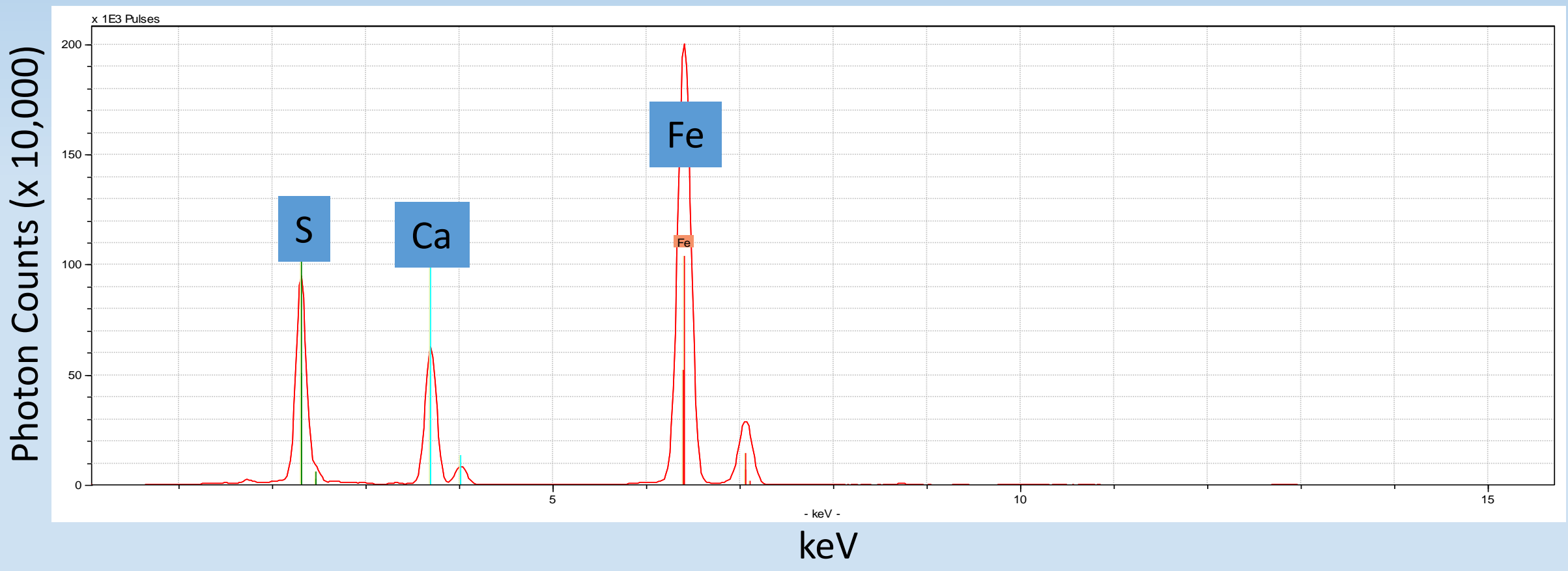




\section{Objectives}

The objective of this activity is to identify rock powders based only on their major element compositions as determined by XRF.

\section{Instructions}

A set of rocks commonly found in the Michigan Basin has been provided (Table 1). These rocks have been powdered and placed into the vials labeled A-F. The whole rocks are fairly easy to tell apart, but as you can see, it is quite difficult to discriminate between the white powders (except the hematite, of course). Use the raw
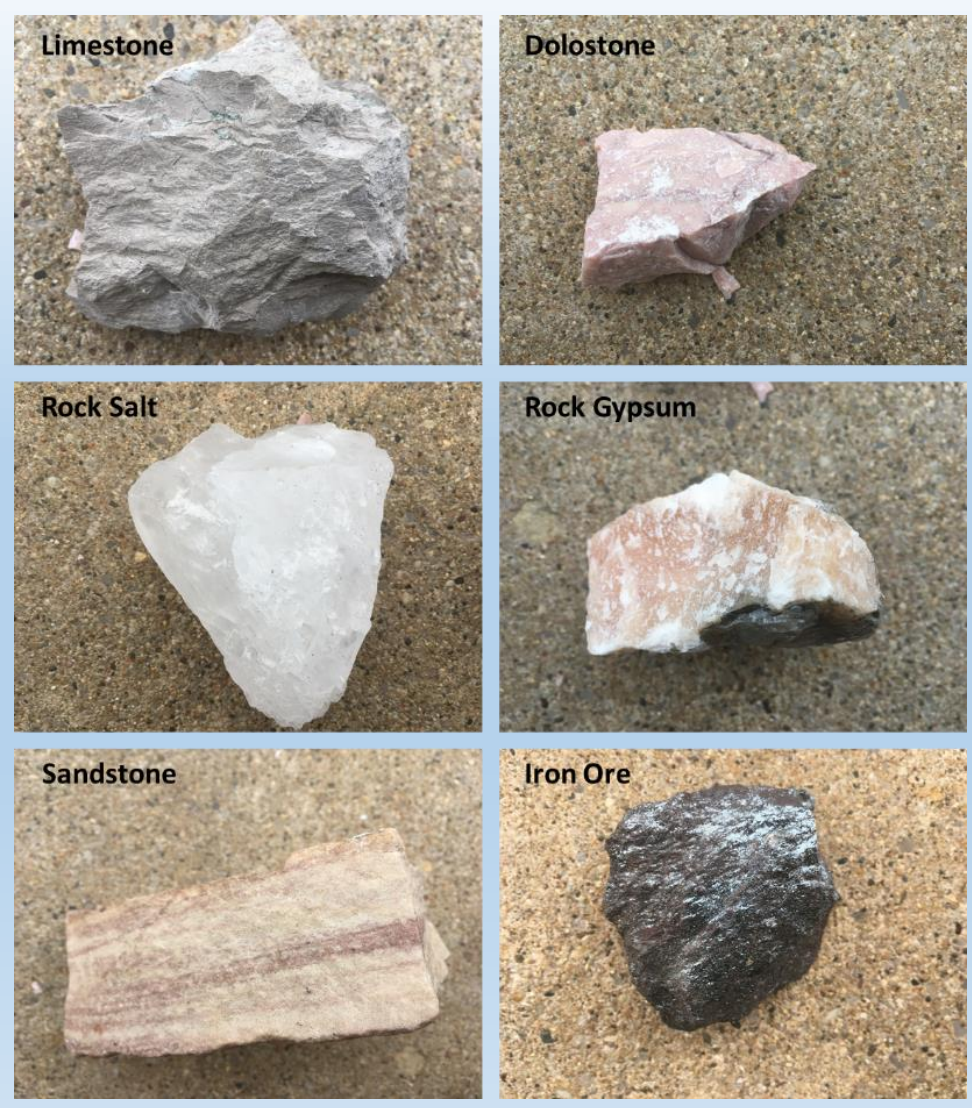
XRF spectra provided to match the powdered samples to their whole rock counterparts.

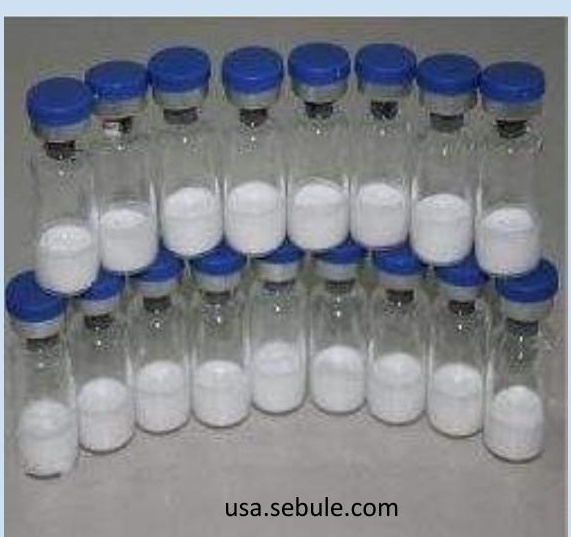

XRF - quantitative, quick, analytical technique
\begin{tabular}{l|l|l|l|}
\hline Rock Name & Mineralogy & Chemical Formula & Chemical name \\
\hline Limestone & calcite, aragonite & $\mathrm{CaCO}_{3}$ & calcium carbonate \\
\hline Dolostone & dolomite & $\mathrm{CaMg}\left(\mathrm{CO}_{3}\right)_{2}$ & calcium-magnesium carbonate \\
\hline Rock Salt & halite & $\mathrm{NaCl}$ & sodium chloride \\
\hline Rock Gypsum & gypsum & $\mathrm{CaSO}_{4}$ & calcium sulfate \\
\hline Sandstone & quartz & $\mathrm{SiO}_{2}$ & silicon dioxide \\
\hline Specular Hematite & hematite, mica & $\mathrm{Fe}_{2} \mathrm{O}_{3}$ & iron oxide \\
\hline
\end{tabular}




\section{Forensic X-ray Fluorescence: Hit-and-Run}

Image that you're a forensic scientist whose task it is to determine what happened in a hit-and-run car accident. At the crime scene, microscopic glass fragments from the car's windshield are found on the victim's body (Glass A). The police locate an abandon car with serious damage that fits a witness's description. The owner of the vehicle (i.e. suspect \#1) claims his vehicle was stolen earlier that night and he wasn't involved with the accident. After obtaining a search warrant, your team searches the suspect's home and collects a small glass fragment embedded in the suspect's jacket (Glass B).

Both glass samples have been analyzed with the handheld XRF to determine their trace element compositions. Here are the resulting spectra

\section{Glass A}

Glass B 


\section{Forensic X-ray Fluorescence: Hit-and-Run}

What elements do the glass samples have in common? What elements are unique? Do these samples have the same origin?

These samples likely do not have the same origin due the presence of $\mathrm{Ce}$ in Glass

$B$. The samples are also different in their relative amounts of $\mathrm{Zr}$, with Glass $\mathrm{A}$ having more $\mathrm{Zr}$ than $\mathrm{B}$. Both samples are the same in the amount of all other elements.

Is there enough forensic evidence to say the suspect was or wasn't involved in the crime?

These data do not support the claim that the glass on the suspect's jacket was the same as the glass from the crime scene and on the victim. It doesn't rule out the involvement of the suspect.

Glass A Glass B 

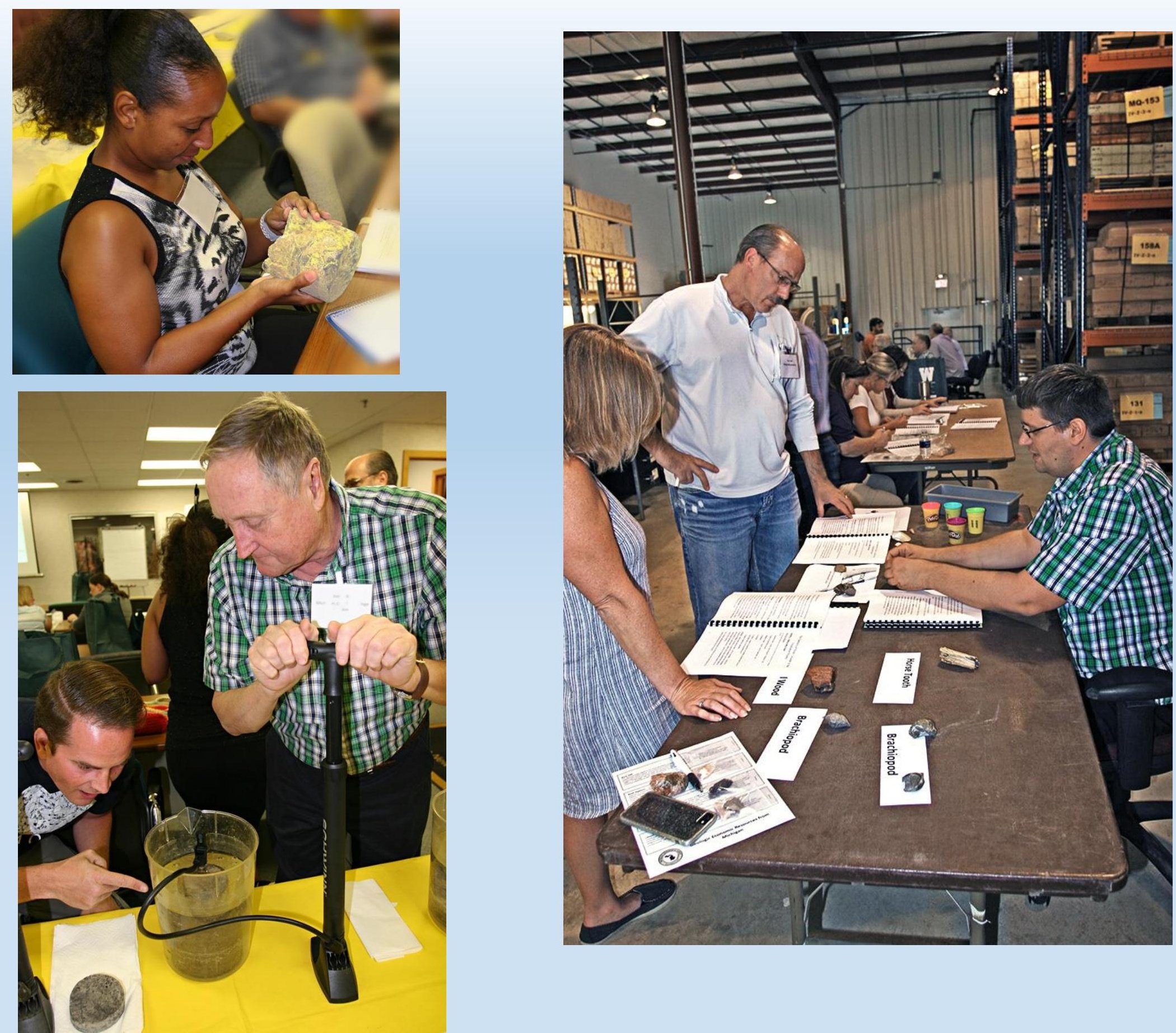


\section{Discussion}

\section{Sessions}

- Teacher-mediated discussion in small groups

- Discussion of how activities/lesson plans fit into NGSS

- Discussion of multidisciplinary/int egrated science using examples from geosciences to reinforce chemistry and physics concepts

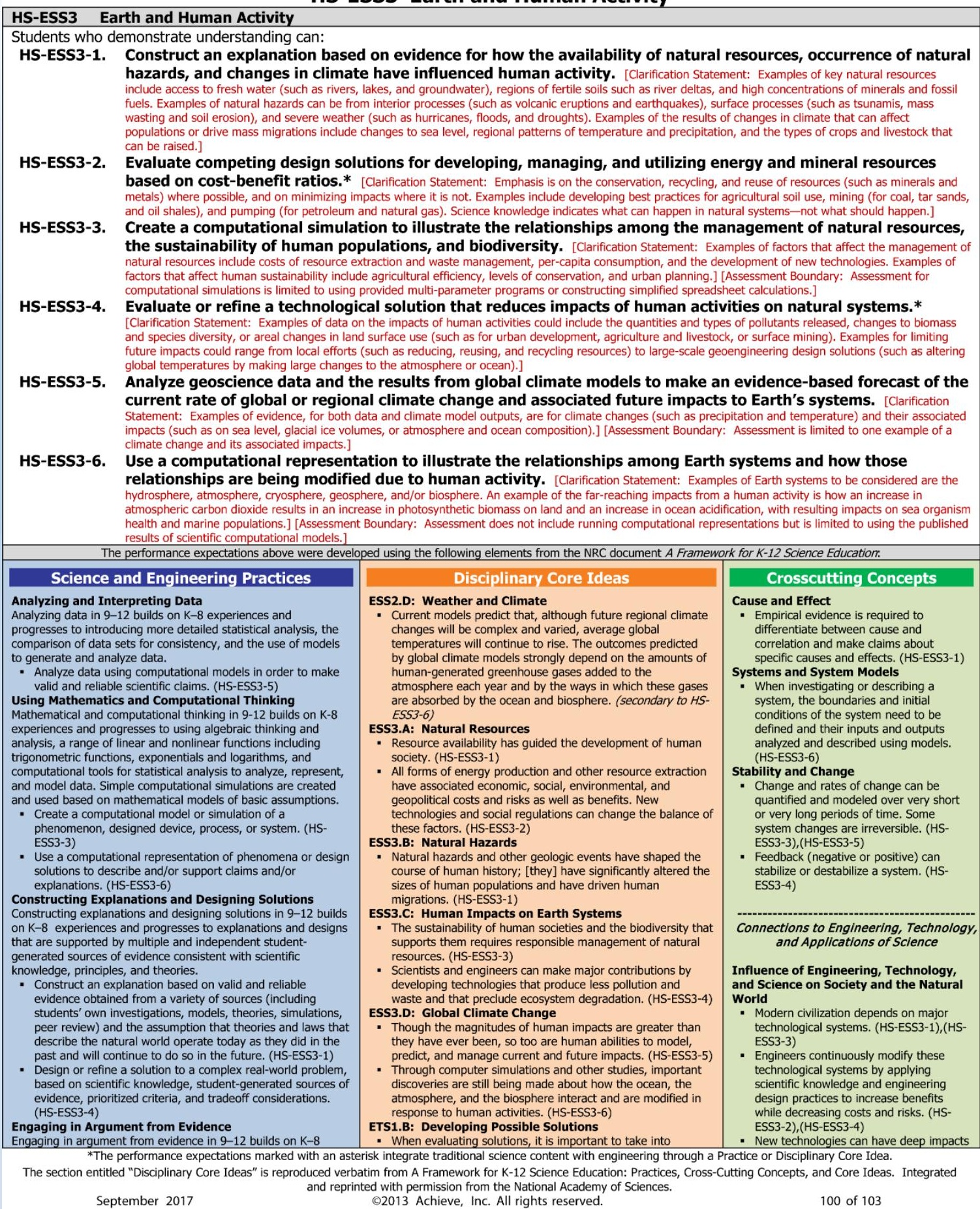


2. This workshop allowed

1. This workshop increased my familiarity with how geoscientists use geological materials as sources of quantitative composition, and common chemical data. me to better appreciate the relationship between common geological materials, their chemical to determine the chemical societal uses. a basic understanding of how X-ray fluorescence spectrometry can be used composition of geological materials.
3. This workshop gave me

$\begin{array}{lll}5 & 5 & 5 \\ 5 & 5 & 5 \\ 5 & 5 & 5 \\ 5 & 5 & 5 \\ 5 & 5 & 5 \\ 5 & 5 & 5 \\ 5 & 5 & 5 \\ 5 & 5 & 5 \\ 5 & 5 & 5 \\ 4 & 4 & 5 \\ 5 & 5 & 5 \\ 3 & 4 & 4 \\ 5 & 5 & 5 \\ 5 & 4 & 5 \\ 5 & 4 & 5\end{array}$


9. How much do you think you now understand about using XRF spectroscopy to study the elemental composition of geologic materials as a result of participating in this workshop?
10. To what extent 11. I plan to did the lessons and use the lessons teaching materials and teaching provided in this materials workshop align provided in this with state science workshop in my standards? classes.

$\begin{array}{lllll}4 & 5 & 5 & 1 . & \text { It increased teacher } \\ 5 & 5 & 5 & & \text { knowledge } \\ 4 & 5 & 5 & 2 . & \text { The materials provided } \\ 4 & 5 & 4 & & \text { were aligned with MI } \\ 5 & 5 & 5 & & \text { Science Standards } \\ 5 & 5 & 5 & 3 . & \text { Teachers were willing to } \\ 4 & 4 & 4 & \text { use the materials in } \\ 5 & 5 & 5 & \text { their classrooms } \\ 4 & 5 & 5 & \\ 4 & 5 & 4 & \\ 5 & 5 & 5 & \\ 3 & 3 & 3 & \\ 4 & 4 & 4 & \\ 4 & 4 & 4 & \\ 4 & 4 & 4 & \end{array}$

\section{The Workshop was} effective:

1. It increased teacher

2. The materials provided were aligned with MI Science Standards use the materials in their classrooms 


\section{Conclusions}

- Emphasize connections between Geosciences, Chemistry and Physics

- Better alignment with NGSS

- Provide examples across disciplines that teachers can use

- Hands-on activities - more engaging to students and teachers

- Data sets authentic and quantitative: math literacy, graph comprehension, statistical analysis of geological data

- More rigorous approach to outreach and K-12 education portable tech and "instantaneous testing" 